\title{
Assessment of IPv4 and IPv6 Networks with Different Modified Tunneling Techniques using OPNET
}

\author{
Asif Khan Babar ${ }^{1}$ \\ University of Sindh \\ Dadu Campus \\ Dadu, Pakistan
}

\author{
Zulfiqar Ali Zardari ${ }^{2}$, Sirajuddin \\ Qureshi ${ }^{4}$, Song Han $^{5}$ \\ Faculty of Information Technology \\ Beijing University of Technology \\ Beijing, China
}

\author{
Nazish Nawaz Hussaini ${ }^{3}$ \\ Institute of mathematics and \\ Computer Sciences and IMCS \\ University of Sindh \\ Jamshoro
}

\begin{abstract}
Currently, all the devices are using Internet protocol version 4 (IPv4) to access the internet. IP addresses of the IPv4 are now depleted from IPv4 pool announced by IANA (Internet Assigned Number Authority) in February 2011. To solve this issue Internet protocol version 6 (IPv6) is launched. But the main problem is current devices can't support directly IPv6 that causes various compatibility issues. Many researchers have proposed various techniques, but still, their efficiency and performance is a big challenge. This study examines several mechanisms of transition IPv6 the backbone of multiprotocol label switching (MPLS) to evaluate \& compare their performances. It involves comparing different performance metrics and manual tunneling tunnel efficiency metrics. The main goal of this paper is to examine the dissimilar tunneling techniques and find out which tunneling method is better in all performance, which increases network performance. Experimental results show that ISATAP is better performance in all metrics.
\end{abstract}

Keywords-ISATAP; tunneling techniques; IPv4; IPv6; network performance

\section{INTRODUCTION}

Due to the rapid growth of population demand for IP addresses has increased more and more [1-3]. Eventually, IP addresses of IPv4 pool is completely exhausted. IANA announced on 3 February 2011 that no. of IPv4 addresses are almost exhausted. Many companies and organizations are moving towards IPv6 addresses. IPv4 is 32 bit long and supports an address of only 32-bit, meaning 4.3 billion. IPv6 is 128 bit long and includes an enormous amount of addresses, i.e. trillions of trillion addresses are now accessible. MPLS is a mechanism for packet labeling [4-7]. It is extremely scalable system and commonly utilized in transmission technology by internet service suppliers. It plays a vital role in the IPv4 backbone network for companies. MPLS examines the labels and forward data packets discovered on the label instead of searching for hard routing and examine the packets. Companies, use the backbone of MPLS to link offices and sites together remotely. The integration of IPv6 facilities in the MPLS infrastructure can be seen as ordinary progress by service suppliers and businesses using MPLS networks [810].The MPLS backbone provides the option of connecting IPv6 network, using the existing IPv4 network. When using the IPv4 MPLS backbone current, several ways to connect to IPv6 islands. Because the cost of updating the spine in whole or in part is greater and needs network updates, therefore transition mechanisms are deployed. The theory of MPLS is developed and considered as the hybrid technology of ATM and IP. This paper evaluates distinct techniques for clouting current IPv4 network MPLS additional IPv6 facilities lacking the need for backbone adjustments. These techniques are used to isolate IPv6 domains to interact on the present IPv4 MPLS backbone [11]. In the IPV6 tunnels among customer edge and customer edge CE-to-CE routers together with manual tunnels, ISATAP tunnels, 6to4 tunnels. IPV6 tunnels between supplier edge and supplier edge PE-to-PE routers along with manual tunnels, IPV4 automatic tunnels, ISATAP tunnels, and 6to4 tunnels. This paper analyzes performance parameters, i.e. delays in data packets, jitter, and throughput of the network above mentioned techniques and performs statistical analysis [12-15]. The purpose of doing this study is to investigate the various tunneling mechanisms which run both network IPv4 and IPv6. After the deployment of these mechanisms find out the best transition mechanism that provides the highest throughput with very low delay and jitter in the network. For better understanding, the scenarios are shown below in Fig. 1. The figure shows this research paper consist of four phases. Each phase provides the evaluation of the research intention is acclimated. The emulation is done by Graphical Network Simulator (GNS3) tool. Network simulation and data gathering are done by (OPNET) tool. In the last phase data analysis is conducted by MS-office 2013.

\section{A. Contributions/ Findings}

The findings of these studies and contributions described as follows:

- Proposed work covers the shortage of IPv4 addresses and provides full IPv6 connectivity.

- Proposed study assessment of a sequence of IPv6 multiprotocol label switching (MPLS) transition mechanisms.

- Analyzing the transition system and identifying which mechanism is best performed in terms of the smallest delay lowest jitter and the greatest performance. 


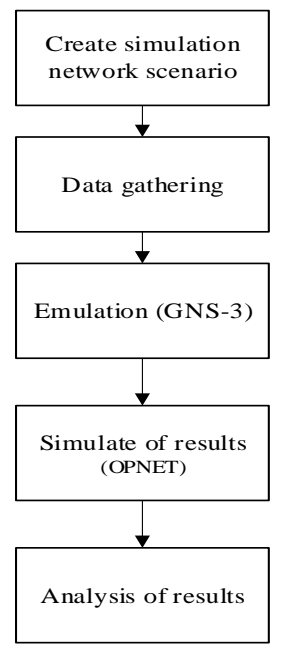

Fig. 1. Proposed Methodology Flowchart.

Our research paper is divided into six sections, the second section of the paper describes some existing techniques and drawbacks, the third section presents the methodology of the proposed analysis, and the fourth section is about the simulation results and their discussion. The fifth section is all about analysis of data through different statistical methods like ANOVA, F-test and T-test, in the last section is the conclusion.

\section{RELATED RESEARCH}

The various researchers have proposed different tunneling mechanisms, but there are some drawback is still in the network. Following Table I show some tunneling mechanisms and their drawbacks.

TABLE. I. SUMMARY OF PREVIOUS WORK AND THEIR DRAWBACKS

\begin{tabular}{|l|l|l|l|}
\hline S. No. & Author & Technique & Drawbacks \\
\hline 01 & Dr vadym Kaptur & $\begin{array}{l}\text { Tunneling, NAT, } \\
\text { Dual-stack }\end{array}$ & $\begin{array}{l}\text { Old technique and } \\
\text { not ideal }\end{array}$ \\
\hline 02 & Luke smith & $\begin{array}{l}\text { Dual-stack and manual } \\
\text { tunnel }\end{array}$ & $\begin{array}{l}\text { A circumstance } \\
\text { where point-to- } \\
\text { multipoint tunnels }\end{array}$ \\
\hline 03 & Zeeshan Ashraf & $\begin{array}{l}\text { OSPF V3 in IPV6 } \\
\text { tunneling methods }\end{array}$ & $\begin{array}{l}\text { Only focus on } \\
\text { OSPF protocol }\end{array}$ \\
\hline 04 & M. S. Ali & $\begin{array}{l}\text { Traffic sent from IPV4 } \\
\text { network to IPV6 } \\
\text { network and only } \\
\text { method is used that is } \\
\text { 6to4 method in } \\
\text { OPNET tool }\end{array}$ & $\begin{array}{l}\text { This research only } \\
\text { focuses on one } \\
\text { method, but other } \\
\text { methods are } \\
\text { remaining }\end{array}$ \\
\hline 05 & Sami Salih & 6vpe & $\begin{array}{l}\text { Onlyfocused delay } \\
\text { performance } \\
\text { parameters. }\end{array}$ \\
\hline 06 & $\begin{array}{l}\text { Yashwin Sookun, } \\
\text { Vandana Bassoo }\end{array}$ & $\begin{array}{l}\text { Performance Analysis } \\
\text { of IPv4/IPv6 } \\
\text { Transition } \\
\text { Techniques }\end{array}$ & $\begin{array}{l}\text { Network and } \\
\text { traffic load is high }\end{array}$ \\
\hline 07 & $\begin{array}{l}\text { N. } \\
\text { Chuangchunsong } \\
\text { at al }\end{array}$ & $\begin{array}{l}\text { Mohammad } \\
\text { Aazam et al }\end{array}$ & DS-Lite, 4over6, \\
\hline 08 & $\begin{array}{l}\text { Teredo, ISATAP } \\
\text { defined clearly }\end{array}$ \\
\hline
\end{tabular}

\section{PRoposed ANALysis}

For simulation optimized network engineering tools (OPNET) has been used [16]. The Customer edge to customer edge ( $\mathrm{CE}$ to $\mathrm{CE}$ ) and the provider edge to provider edge (PE to $\mathrm{PE})$ routers are placed. For configuration of routers wellknown emulation is used, called graphical network simulator (GNS3) [17-19]. For simulation, all configurations are imported to the OPNET environment. External Border Gateway Protocol (EBGP) and Multiprotocol Border Gateway Protocol (MP-BGP) are used for PE routers, CE routers for remote access to PE router in MPLS whereas Interior Gateway Protocol (IGP) and Open Shortest Path First (OSPF) are used inside the MPLS. For suitable deployments configured for IPv4 and IPv6 networks, but it also depends on the transition mechanisms. MPLS cloud set to be in IPv4-enabled and IPv6enabled customers and servers for the transition processes. If customers need to interact with servers on separate islands on each IPv6 island, they must cross the cloud of the IPv4 MPLS. Then a total of eight tunneling scenarios were configured for the various tunneling mechanisms shown in Table II. All customers and servers have IPv6 allowed configuration. These tunneling processes were used to traffic IPv6 throughout the current IPv4 network by encapsulating IPv6 packets in the IPv4 header. Data packet will be decapsulated at the end node of the tunnel, and it will be removed from the IPv4 packet header. An actual data packet of IPv6 transferred to Wellmatched Tunnels, and it configured remaining four routers among provider edge routers.

TABLE. II. IPV6 TRANSITION MECHANISMS

\begin{tabular}{|c|c|}
\hline \multicolumn{2}{|l|}{ Manual tunnel } \\
\hline IPv4 MPLS backbone & Manual tunnel $\mathrm{CE}$ to $\mathrm{CE}$ \\
\hline IPv4 MPLS backbone & Manual tunnel PE to PE \\
\hline \multicolumn{2}{|l|}{ Automatic tunnel } \\
\hline IPv4 MPLS backbone & Manual tunnel $\mathrm{CE}$ to $\mathrm{CE}$ \\
\hline IPv4 MPLS backbone & Manual tunnel PE to PE \\
\hline \multicolumn{2}{|l|}{6 to4 tunnel } \\
\hline IPv4 MPLS backbone & Manual tunnel CE to CE \\
\hline IPv4 MPLS backbone & Manual tunnel PE to PE \\
\hline \multicolumn{2}{|l|}{ GRE tunnel } \\
\hline IPv4 MPLS backbone & Manual tunnel $\mathrm{CE}$ to $\mathrm{CE}$ \\
\hline IPv4 MPLS backbone & Manual tunnel PE to PE \\
\hline \multicolumn{2}{|l|}{ ISATAP tunnel } \\
\hline IPv4 MPLS backbone & Manual tunnel $\mathrm{CE}$ to $\mathrm{CE}$ \\
\hline IPv4 MPLS backbone & Manual tunnel PE to PE \\
\hline
\end{tabular}

The CEs were intended to be allowed for IPv4 and IPv6 in the event of CE-to CE tunneling, and only IPv4 was configured for PE routers and all IPv6-enabled client and server configuration. After the encapsulating process of IPv6 data packets in the header of the IPv4 network, these tunneling procedures were used to traffic IPv6 across the existing IPv4 network. The packet will be decapsulated at the tunnel end node and the packet header IPv4 will be deleted. It will then forward the initial IPv6 packet to its final IPv6 place. Next, the 
6PE, Native IPv6, and dual-stack transition devices were configured. The MPLS cloud is allowed for 6PE with PE routers supported by IPv4 and IPv6, CE routers supported by IPv6 and PE router supported by IPv4. The MPLS key infrastructure is unaware of IPv6 in the 6PE transition system and to support IPv4/IPv6; only PE routers are updated and 6PE. The 6PE routers use the MP-BGP over IPv4 to exchange accessibility information across the network in a transparent manner.

\section{EXPERIMENTAL SETUP AND ANALYSIS}

In our proposed technique, we have deployed IPv4 and IPv6 networks with MPLS technology. For the simulation of the network, OPNET simulator is used to verify both networks are working smoothly with five routers as shown in Fig. 2. For each of 11 situations, the model was run for five hours with three seeds. Every second, the metrics were set to be gathered, leading in 18000.

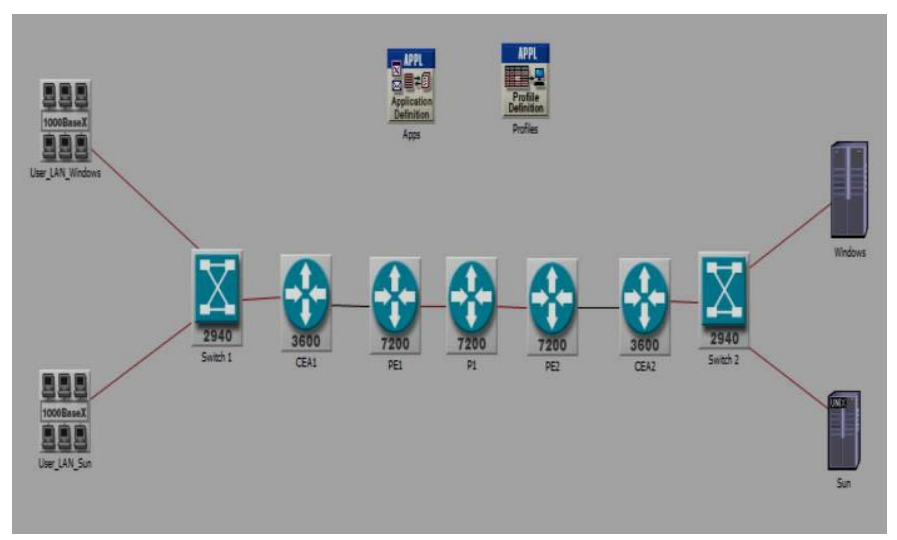

Fig. 2. OPNET Network Simulation.

\section{Simulation SetuP}

The five thousand four hundred values gathered for every metric are highly greater, as shown in the statistics above the numbers are close to one another. As a consequence, the statistical investigation is conducted to define if the mechanisms for each performance metric have any statistically significant distinctions. The statistical analysis conducted to assess the information gathered is described in Section 4.

OPNET Average End-to-End delay for all scenarios as shown in Fig. 3. X-axis is total time in minute's total running time for simulation is 5 hours and $\mathrm{Y}$-axis is time for delay measured in seconds.

OPNET Average End-to-End jitter for all scenarios as shown in Fig. 4. X-axis is total time in minute's, total running time for simulation is 5 hours and $\mathrm{Y}$-axis is time for jitter that is delay that is IP delay variation is seconds.

OPNET average End-to-End Throughput for overall simulation as shown in Fig. 5. X-axis is total time in minute's total running time for simulation is 5 hours and $\mathrm{Y}$-axis is time for throughput of the network that process how many packets can process in a given amount of time.

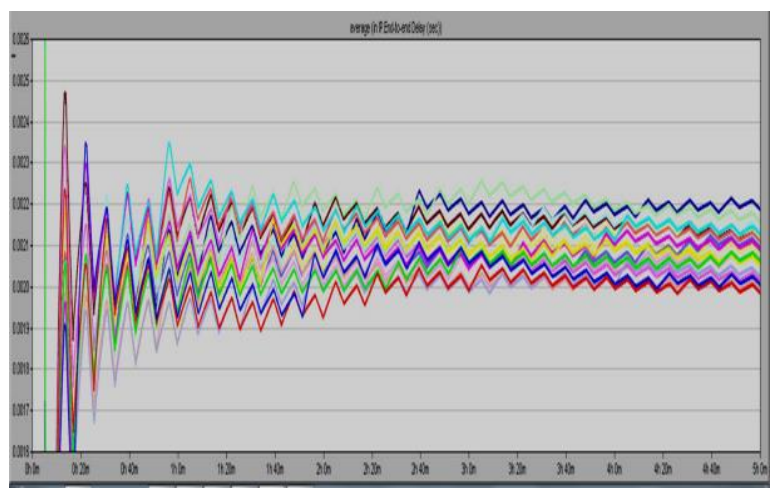

Fig. 3. OPNET Average End-to-End Delay for All Scenarios.

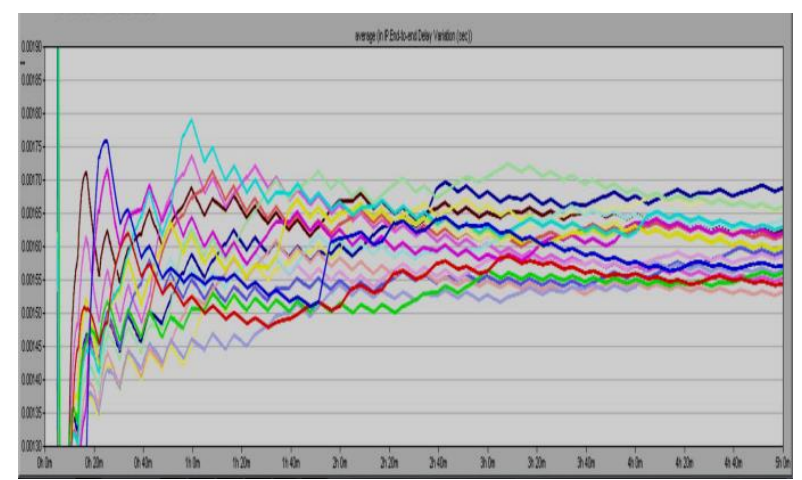

Fig. 4. OPNET Average End-to-End Jitter for All Scenarios.

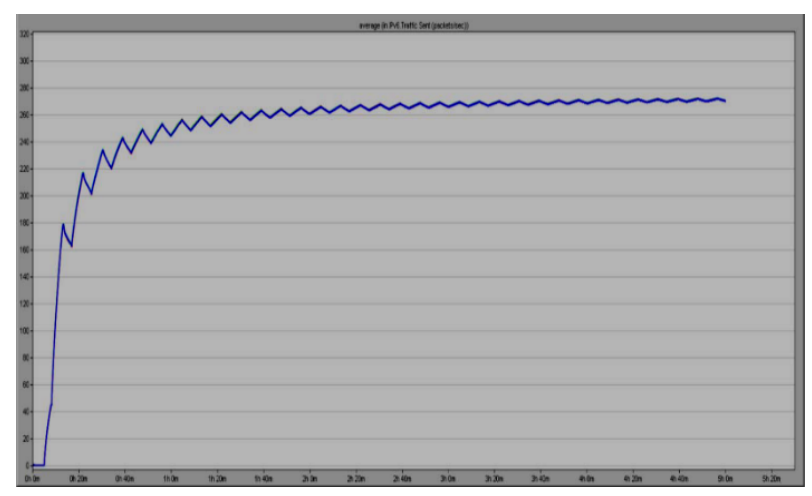

Fig. 5. OPNET Average Throughput for All Scenarios.

\section{ANALYSIS OF THE RESUltS}

Investigation of the collected data and evaluated the resultant data. Methods Below were used to perform the statistical analysis.

- Analysis of variance (ANOVA)

- F-TEST

- T-TEST

ANOVA was used to determine if there is statistically significant difference in means among the scenarios F-Test was used to determine whether modifications were equivalent and whether the mean of one system differed from the mean of the other. Finally, either two sample T-test using degree of freedom was used to determine if the mean of one mechanism is different from the mean of another mechanism. 


\section{A. Scenario. 01 Customer Edge to Customer Edge (CE-to-} CE)

To calculate significant variations between the metrics of IPv6 CE-to-CE tunneling processes (delay, jitter, throughput) and Calculate which method is the best.

1) Analysis of delay: For ANOVA, the hypothesis below has been recognized. - Null Hypothesis (H0): delay implies equivalent to $\mathrm{CE}$-to-CE tunneling processes Alternative Hypothesis (H1): for CE-to-CE tunneling processes, at least one delay implies different from other means.

TABLE. III. ANOVA RESULTS FOR DELAY CE-TO-CE TUNNEL

\begin{tabular}{|l|l|l|l|l|}
\hline \multicolumn{4}{|l|}{ ANOVA: Single Factor } \\
\hline Specified group & Total & Sum (Quantity) & Average & Difference \\
\hline $\begin{array}{l}\text { Manual CE- } \\
\text { CE }\end{array}$ & 51699 & 107.4725336 & 0.0020970 & 2.44585 \\
\hline Auto CE & 51762 & 106.4065222 & 0.0020822 & 2.44083 \\
\hline GRE CE-CE & 51758 & 109.4823187 & 0.0031417 & 2.5934 \\
\hline 6to4 CE-CE & 51792 & 108.815763 & 0.0034448 & 2.53934 \\
\hline $\begin{array}{l}\text { ISATAPCE- } \\
\text { CE }\end{array}$ & 51750 & 105.403224 & 0.0030568 & 2.33172 \\
\hline
\end{tabular}

\begin{tabular}{|c|c|c|c|c|c|c|}
\hline (contd.) & & & & & & \\
\hline $\begin{array}{l}\text { Source of } \\
\text { variation }\end{array}$ & $S S$ & $D F$ & $M S$ & $F$ & $\begin{array}{l}P- \\
V A L U \\
E\end{array}$ & $F$-critical \\
\hline $\begin{array}{l}\text { Between } \\
\text { Groups }\end{array}$ & $\begin{array}{l}0.00012 \\
7451\end{array}$ & 4 & $\begin{array}{l}4.248 \\
35\end{array}$ & \multirow{3}{*}{$\begin{array}{l}16.9600 \\
9107\end{array}$} & \multirow{3}{*}{5.2} & \multirow{3}{*}{$\begin{array}{l}2.37 \\
\text { F test }>\text { F } \\
\text { critical } \\
\text { Reject } \\
\text { null } \\
\text { Hypothesi } \\
\text { s }\end{array}$} \\
\hline $\begin{array}{l}\text { Within } \\
\text { Groups }\end{array}$ & $\begin{array}{l}0.51942 \\
6123\end{array}$ & $\begin{array}{l}25921 \\
1\end{array}$ & $\begin{array}{l}2.504 \\
91\end{array}$ & & & \\
\hline Total & $\begin{array}{l}0.51955 \\
3573\end{array}$ & $\begin{array}{l}25921 \\
5\end{array}$ & & & & \\
\hline
\end{tabular}

The result for delay performance metrics from CE-to-CE tunnel is shown in above Table III. where $\mathrm{F}$ test $>\mathrm{F}$ critical for Seeing that null hypothesis is rejected that reason it is enough evidence that at least one delay mean is different from other delay mean for all scenarios.

2) F-Test for delay CE-to-CE tunnel: F test was used to evaluate if the variances are equal using the hypothesis given below.

Null hypothesis $(\mathrm{H} 0)=$ delay variance $\mathrm{i}=$ delay variance

Alternative hypothesis $(\mathrm{H} 1)=$ delay variance $\mathrm{i}=<$ delay variance $\mathrm{j}$.

The result shown in Table IV since F0>F $\alpha \mathrm{n} 1-1, \mathrm{n} 2-2$ is not true then null hypothesis is not rejected and it is enough evidence that delay variances are equal in that condition we will perform T-test to find which delay mean is less than the others.

3) T-Test for delay CE-to-CE tunnel: The results are shown in Table $\mathrm{V}$, since $\mathrm{t} 0<-\mathrm{t} \alpha, \mathrm{n} 1-1, \mathrm{n} 2-2$ then the null hypothesis was rejected and hence it is enough evidence that delay means of Manual CE-to-CE and Automatic CE-to-CE is less than the 6to4 CE-to-CE and GRE CE-to-CE. Additionally ISATAP CE-to-CE tunnel is less than the GRE CE-to-CE tunnel.
TABLE. IV. F-TEST RESUlt FOR DELAy CE-TO-CE TUNNEL

\begin{tabular}{|l|l|l|l|}
\hline F-TEST & n1,n2 is the degree of freedom $\quad$ f0=S12/S22 \\
\hline $\begin{array}{l}\text { Transition } \\
\text { Mechanisms }\end{array}$ & $\begin{array}{l}\boldsymbol{F} \boldsymbol{\alpha , n 1 -} \\
\mathbf{1 , n 2 - 2}\end{array}$ & $\boldsymbol{F 0}$ & $\begin{array}{l}\text { Test } \text { if } \boldsymbol{F 0}>\boldsymbol{F} \boldsymbol{\alpha} \\
\boldsymbol{n 1}-\mathbf{1 , n 2 - 2}\end{array}$ \\
\hline Auto CE \& 6to4 CE & one & 0.961206111 & Negative \\
\hline Auto CE \& GRE CE & one & 0.941160555 & Negative \\
\hline $\begin{array}{l}\text { Auto CE \& ISATAP } \\
\text { CE }\end{array}$ & one & 0.801237 & Negative \\
\hline $\begin{array}{l}\text { Manual CE \& 6to4 } \\
\text { CE }\end{array}$ & one & 0.963112573 & Negative \\
\hline $\begin{array}{l}\text { Manual CE \& GRE } \\
\text { CE }\end{array}$ & one & 0.943143 & Negative \\
\hline $\begin{array}{l}\text { Manual CE \& } \\
\text { ISATAP CE }\end{array}$ & one & 0.85365 & Negative \\
\hline 6to4 CE \& GRE CE & one & 0.979155778 & Negative \\
\hline $\begin{array}{l}\text { 6to4 CE \& ISATAP } \\
\text { CE }\end{array}$ & one & 0.89125 & Negative \\
\hline
\end{tabular}

TABLE. V. T-Test Result For Delay CE-To-CE TunNel

\begin{tabular}{|c|c|c|c|}
\hline \multicolumn{4}{|l|}{ Two Sample T-Test } \\
\hline Transition mechanism & $\begin{array}{l}t \alpha \\
n 1+n 2-2\end{array}$ & to & $\begin{array}{l}\text { Test if } t 0<-t \alpha, \\
n 1+n 2-2\end{array}$ \\
\hline Auto CE \& 6to4 CE & 1.63 & -4.25017473 & YES \\
\hline Auto CE \& GRE CE & 1.63 & -6.06411939 & YES \\
\hline $\begin{array}{l}\text { Auto CE \& ISATAP } \\
\text { CE }\end{array}$ & 1.63 & $\begin{array}{l}- \\
3.638063334\end{array}$ & YES \\
\hline $\begin{array}{l}\text { Manual CE \& 6to4 } \\
\text { CE }\end{array}$ & 1.63 & $\begin{array}{l} \\
5.453454824\end{array}$ & YES \\
\hline $\begin{array}{l}\text { Manual CE \& GRE } \\
\text { CE }\end{array}$ & 1.63 & $-\overline{1.820066369}$ & YES \\
\hline $\begin{array}{l}\text { Manual CE \& } \\
\text { ISATAP CE }\end{array}$ & 1.63 & $-\overline{2.639061371}$ & YES \\
\hline 6to4 CE \& GRE CE & 1.63 & $\begin{array}{l}- \\
3.999067322\end{array}$ & YES \\
\hline $\begin{array}{l}\text { 6to4 CE \& ISATAP } \\
\text { CE }\end{array}$ & 1.63 & $\begin{array}{l}- \\
2.638067771\end{array}$ & YES \\
\hline
\end{tabular}

4) Analysis of jitter: Jitter is also analyzed using similar techniques. The ANOVA results in Table VI were obtained.

TABLE. VI. ANOVA RSULTS FOR JITTER CE-TO-CE TUNNEL

\begin{tabular}{|c|c|c|c|c|c|c|c|c|}
\hline \multicolumn{9}{|c|}{ ANOVA: Single Factor } \\
\hline \multicolumn{2}{|l|}{ Groups } & \multicolumn{2}{|c|}{ Count } & \multicolumn{2}{|c|}{ Sum } & \multicolumn{2}{|c|}{ Average } & Variance \\
\hline \multicolumn{2}{|c|}{ Manual CE-CE } & \multicolumn{2}{|c|}{51753} & \multicolumn{2}{|c|}{82.6607} & \multicolumn{2}{|c|}{0.001597} & 4.05 \\
\hline \multicolumn{2}{|c|}{ Auto CE-CE } & \multicolumn{2}{|c|}{51864} & \multicolumn{2}{|c|}{82.52443} & \multicolumn{2}{|c|}{0.001591} & 4.14 \\
\hline \multicolumn{2}{|c|}{ GRE CE-CE } & \multicolumn{2}{|c|}{51858} & \multicolumn{2}{|c|}{85.79141} & \multicolumn{2}{|c|}{0.001654} & 4.28 \\
\hline \multicolumn{2}{|c|}{ 6to4 CE-CE } & \multicolumn{2}{|c|}{51892} & \multicolumn{2}{|c|}{84.85763} & \multicolumn{2}{|c|}{0.001635} & 4.37 \\
\hline \multicolumn{2}{|c|}{ ISATAPCE-CE } & \multicolumn{2}{|c|}{51850} & \multicolumn{2}{|c|}{81.33167} & \multicolumn{2}{|c|}{0.001568} & 4.28 \\
\hline \multicolumn{9}{|c|}{ (contd.) } \\
\hline \begin{tabular}{|l|}
$\begin{array}{l}\text { Source } \\
\text { of } \\
\text { variation }\end{array}$ \\
\end{tabular} & \multicolumn{2}{|l|}{$S S$} & $D f$ & & $M S$ & $\boldsymbol{F}$ & $\begin{array}{l}p- \\
\text { value }\end{array}$ & F-critical \\
\hline $\begin{array}{l}\text { Between } \\
\text { Groups } \\
\text { SSB }\end{array}$ & \multicolumn{2}{|c|}{0.000143} & 3 & \multicolumn{2}{|r|}{4.77} & \multirow{3}{*}{113.4597} & \multirow{3}{*}{2.8} & \multirow{3}{*}{$\begin{array}{l}2.604952 \\
\text { F test }>\text { F } \\
\text { critical } \\
\text { Reject Null } \\
\text { Hypothesis }\end{array}$} \\
\hline $\begin{array}{l}\text { Within } \\
\text { Groups } \\
\text { SSW }\end{array}$ & \multicolumn{2}{|c|}{0.087257} & \multicolumn{2}{|c|}{207363} & 4.21 & & & \\
\hline $\begin{array}{l}\text { Total } \\
\text { SST }\end{array}$ & \multicolumn{2}{|c|}{0.0874} & 20736 & & & & & \\
\hline
\end{tabular}


5) F-Test for jitter CE-to-CE tunnel: The results shown in Table VII says that there is enough evidence to support that end-to-end jitter means of different tunneling Manual CE-to$\mathrm{CE}$ and Automatic CE-to-CE are less than 6to4 CE-to-CE and ISATAP CE-to-CE tunnel, and 6to4 CE-to-CE has lower mean jitter than ISATAP CE-to-CE.

6) T-Test for jitter CE-to-CE tunnel: The results shown in Table VIII says that there is enough evidence to support that end-to-end jitter means of different tunneling Manual CE-to$\mathrm{CE}$ and Automatic CE-to-CE are less than 6to4 CE-to-CE and ISATAP CE-to-CE tunnel, and 6to4 CE-to-CE has lower mean jitter than ISATAP CE-to-CE.

\section{B. Scenario. 02 Provider Edge to Provider Edge (PE-to-PE)}

1) ANOVA results for delay PE-to-PE tunnel: The result for delay PE-to-PE performance parameters are shown in Table IX. Since Ftest $>$ Fcritical therefore the Null Hypothesis is rejected and there is enough evidence to demonstrate that at least one delay mean is different from other delay means among the all scenarios.

TABLE. VII. F-TEST RSULTS FOR JITTER CE-TO-CE TUNNEL

\begin{tabular}{|l|l|l|l|}
\hline F-TEST & n1,n2 is the degree of freedom & f0=S12/S22 \\
\hline $\begin{array}{l}\text { Transition } \\
\text { Mechanisms }\end{array}$ & $\begin{array}{l}\boldsymbol{F} \boldsymbol{\alpha}, \boldsymbol{n 1 - 1 ,} \\
\mathbf{n 2 - 2}\end{array}$ & $\boldsymbol{F O}$ & $\begin{array}{l}\text { Test } \text { if } \boldsymbol{F} \mathbf{0}>\boldsymbol{F} \boldsymbol{\alpha} \text { n1- } \\
\mathbf{1 , n 2 - 2}\end{array}$ \\
\hline Auto CE \& 6to4 CE & one & 0.945501655 & Negative \\
\hline Auto CE \& GRE CE & one & 0.967344952 & Negative \\
\hline $\begin{array}{l}\text { Auto CE \& ISATAP } \\
\text { CE }\end{array}$ & one & 0.922723464 & Negative \\
\hline $\begin{array}{l}\text { Manual CE \& 6to4 } \\
\text { CE }\end{array}$ & one & 0.945787554 & Negative \\
\hline $\begin{array}{l}\text { Manual CE \& GRE } \\
\text { CE }\end{array}$ & one & 0.976769838 & Negative \\
\hline $\begin{array}{l}\text { Manual CE \& } \\
\text { ISATAP CE }\end{array}$ & one & 0.944407759 & Negative \\
\hline 6to4 CE \& GRE CE & one & 0.956819337 & Negative \\
\hline $\begin{array}{l}\text { 6to4 CE \& ISATAP } \\
\text { CE }\end{array}$ & one & 0.945066522 & Negative \\
\hline
\end{tabular}

TABLE. VIII. T-TEST RSULTS FOR JITTER CE-TO-CE TUNNEL

\begin{tabular}{|l|l|l|l|}
\hline \multicolumn{4}{|l|}{ Two Sample T-Test } \\
\hline Transition mechanism & $\begin{array}{l}\boldsymbol{t} \boldsymbol{\alpha} \\
\boldsymbol{n 1 + n 2 - 2}\end{array}$ & $\boldsymbol{t} \boldsymbol{0}$ & $\begin{array}{l}\text { Test } \text { if } \boldsymbol{t} \mathbf{0}<-\boldsymbol{t} \boldsymbol{\alpha}, \\
\boldsymbol{n}+\boldsymbol{n} \mathbf{2 - 2}\end{array}$ \\
\hline Auto CE \& 6to4 CE & 1.63 & -10.88907171 & YES \\
\hline Auto CE \& GRE CE & 1.63 & -15.68834028 & YES \\
\hline $\begin{array}{l}\text { Auto CE \& ISATAP } \\
\text { CE }\end{array}$ & 1.63 & -11.22907883 & YES \\
\hline $\begin{array}{l}\text { Manual CE \& 6to4 } \\
\text { CE }\end{array}$ & 1.63 & -9.441690775 & YES \\
\hline $\begin{array}{l}\text { Manual CE \& GRE } \\
\text { CE }\end{array}$ & 1.63 & -14.25657544 & YES \\
\hline $\begin{array}{l}\text { Manual CE \& } \\
\text { ISATAP CE }\end{array}$ & 1.63 & -8.88922133 & YES \\
\hline 6to4 CE \& GRE CE & 1.63 & -4.672126496 & YES \\
\hline $\begin{array}{l}\text { 6to4 CE \& ISATAP } \\
\text { CE }\end{array}$ & 1.63 & -9.889071761 & YES \\
\hline
\end{tabular}

TABLE. IX. ANOVA RSULTS FOR DELAY PE-TO-PE TUNNEL

\begin{tabular}{|c|c|c|c|c|c|c|}
\hline \multicolumn{7}{|c|}{ Summary } \\
\hline \multicolumn{2}{|l|}{ Groups } & Count & Sum & \multicolumn{2}{|c|}{ Average } & Variance \\
\hline \multicolumn{2}{|l|}{ Auto PE } & 52022 & 107.5243 & \multicolumn{2}{|c|}{0.001591} & 2.45 \\
\hline \multicolumn{2}{|c|}{ Manual PE } & 52022 & 107.5243 & \multicolumn{2}{|c|}{0.001597} & 2.45 \\
\hline \multicolumn{2}{|c|}{ GRE PE } & 51938 & 108.4176 & \multicolumn{2}{|c|}{0.001654} & 2.39 \\
\hline \multicolumn{2}{|l|}{ 6to4 PE } & 51938 & 108.4080 & \multicolumn{2}{|c|}{0.001635} & 2.39 \\
\hline \multicolumn{2}{|c|}{ ISATAP PE } & 52010 & 106.5133 & \multicolumn{2}{|c|}{0.001568} & 2.57 \\
\hline \multicolumn{7}{|l|}{ (contd.) } \\
\hline $\begin{array}{l}\text { Source } \\
\text { of } \\
\text { variati } \\
\text { on }\end{array}$ & $S S$ & $d f$ & $M S$ & $\boldsymbol{F}$ & $\begin{array}{l}p- \\
\text { value }\end{array}$ & $\begin{array}{l}F- \\
\text { critical }\end{array}$ \\
\hline $\begin{array}{l}\text { Betwe } \\
\text { en } \\
\text { Group } \\
\text { s SSB }\end{array}$ & $\begin{array}{l}0.000127 \\
451\end{array}$ & 3 & $\begin{array}{l}4.24835 \\
\text { E- } 05\end{array}$ & \multirow{3}{*}{$\begin{array}{l}16.96009 \\
107\end{array}$} & \multirow{3}{*}{$\begin{array}{l}0.0296 \\
44\end{array}$} & \multirow{3}{*}{$\begin{array}{l}2.60495 \\
2 \\
\text { F test }> \\
\text { F } \\
\text { critical } \\
\text { Reject } \\
\text { Null } \\
\text { Hypothe } \\
\text { sis }\end{array}$} \\
\hline $\begin{array}{l}\text { Within } \\
\text { Group } \\
\text { s SSW }\end{array}$ & $\begin{array}{l}0.519426 \\
123\end{array}$ & $\begin{array}{l}2073 \\
63\end{array}$ & $\begin{array}{l}2.50491 \\
\text { E- } 06\end{array}$ & & & \\
\hline $\begin{array}{l}\text { Total } \\
\text { SST }\end{array}$ & $\begin{array}{l}0.519553 \\
573\end{array}$ & $\begin{array}{l}2073 \\
66\end{array}$ & & & & \\
\hline
\end{tabular}

2) F-Test results for delay PE-to-PE tunnel: The result is shown in Table $\mathrm{X}$, since $\mathrm{F} 0>\mathrm{F} \alpha \mathrm{n} 1-1, \mathrm{n} 2-2$ is not true then null hypothesis is not rejected and it is enough evidence that delay variances are equal in that condition we will perform $\mathrm{T}$ test to find which delay mean is less than the others.

3) T-Test results for delay PE-to-PE tunnel: The result is shown in Table XI, since t0<-t $\alpha, \mathrm{n} 1-1, \mathrm{n} 2-2$ then the Null Hypothesis was rejected. Therefore there is enough evidence to support that end-to-end delay mean of Manual PE-to-PE and Automatic PE-to-PE are less than the 6to4 PE-to-PE and GRE PE-to-PE. Additionally it demonstrates that ISATAP PEto-PE tunnel is lower delay mean as compare to GRE PE-toPE tunnel.

TABLE. X. F-TEST RSULTS FOR DELAY PE-TO-PE TUNNEL

\begin{tabular}{|c|c|c|c|}
\hline \multicolumn{4}{|l|}{ F-TEST } \\
\hline $\begin{array}{l}\text { Transition } \\
\text { mechanism }\end{array}$ & $\begin{array}{l}F \alpha n 1-1 \\
n 2-1\end{array}$ & Fo & $\begin{array}{l}\text { Test if } F 0>F \alpha \quad n 1- \\
1 \mathrm{n} 2-1\end{array}$ \\
\hline Auto PE \& 6to4 PE & one & 1.024523462 & YES \\
\hline Auto PE \& GRE PE & one & 1.024800865 & YES \\
\hline $\begin{array}{l}\text { Auto PE \& ISATAP } \\
\text { PE }\end{array}$ & one & 1.02525635 & YES \\
\hline $\begin{array}{l}\text { Manual PE \& GRE } \\
\text { PE }\end{array}$ & one & 1.024523462 & YES \\
\hline $\begin{array}{l}\text { Manual PE \& } \\
\text { ISATAP }\end{array}$ & one & 1.024800865 & YES \\
\hline $\begin{array}{l}\text { Manual PE \& 6to4 } \\
\text { PE }\end{array}$ & one & 1.024785256 & YES \\
\hline
\end{tabular}


TABLE. XI. T-TEST RSULTS FOR DELAY PE-TO-PE TUNNEL

\begin{tabular}{|c|c|c|c|}
\hline \multicolumn{4}{|l|}{ Two sample T-TEST } \\
\hline Transition mechanism & $T \alpha, a$ & to & Test if $t 0<-t \alpha, a$ \\
\hline Auto PE \& 6to4 PE & 1.63 & -2.10904 & YES \\
\hline Auto PE \& GRE PE & 1.63 & -2.1273 & YES \\
\hline Auto PE \& ISATAP PE & 1.63 & -2.13886 & YES \\
\hline Manual PE \& 6to4 PE & 1.63 & -2.10904 & YES \\
\hline Manual PE \& GRE PE & 1.63 & -2.12737 & YES \\
\hline Manual PE \& ISATAP & 1.63 & -2.11678 & YES \\
\hline
\end{tabular}

4) ANOVA Results for jitter PE-to-PE tunnel: The result is shown in Table XII, since Ftest $<$ Fcritical the Null Hypothesis was accepted. Therefore there is enough evidence to show that there is no statistically-significant difference among the jitter means of PE-to-PE tunneling mechanisms.

5) ANOVA results for overall throughput: The result of throughput of overall system is shown in Table XIII that shows there is not a significant difference among all the mechanisms.

TABLE. XII. T-ANOVA RSULTS FOR JITTER PE-TO-PE TUNNEL

\begin{tabular}{|l|l|l|l|l|}
\hline \multicolumn{5}{|l|}{ Summary } \\
Groups & Count & Sum & Average & Variance \\
\hline Manual PE & 52021 & 83.55317109 & 0.001606143 & 4.47442 \\
\hline Auto PE & 52021 & 83.55317109 & 0.001606143 & 4.47442 \\
\hline GRE PE & 51937 & 83.54239534 & 0.001608533 & 4.09939 \\
\hline 6to4 PE & 51937 & 83.59333751 & 0.001609514 & 4.09323 \\
\hline ISATAP PE & 52010 & 83.40317009 & 0.001603592 & 4.09221 \\
\hline
\end{tabular}

$$
\text { (contd.) }
$$

\begin{tabular}{|c|c|c|c|c|c|c|}
\hline $\begin{array}{l}\text { Sourc } \\
\text { e of } \\
\text { variati } \\
\text { on }\end{array}$ & $S S$ & $d f$ & $M S$ & $F$ & p-value & F-critical \\
\hline $\begin{array}{l}\text { Betwe } \\
\text { en } \\
\text { Group } \\
\text { s SSB }\end{array}$ & $\begin{array}{l}4.56307 \mathrm{E} \\
-07\end{array}$ & 3 & $\begin{array}{l}1.5210 \\
2 \mathrm{E}-07\end{array}$ & \multirow[b]{2}{*}{$\begin{array}{l}0.354921 \\
286\end{array}$} & \multirow[b]{2}{*}{$\begin{array}{l}0.785586 \\
345\end{array}$} & \multirow{2}{*}{$\begin{array}{l}2.604951 \\
992 \\
\text { F test }<F \\
\text { critical } \\
\text { Accept } \\
\text { Null } \\
\text { Hypothes } \\
\text { is }\end{array}$} \\
\hline $\begin{array}{l}\text { Withi } \\
\mathrm{n} \\
\text { Group } \\
\text { s } \\
\text { SSW }\end{array}$ & $\begin{array}{l}0.089101 \\
094\end{array}$ & $\begin{array}{l}2079 \\
12\end{array}$ & $\begin{array}{l}4.2855 \\
2 \mathrm{E}-07\end{array}$ & & & \\
\hline
\end{tabular}

TABLE. XIII. T-ANOVA RSULTS FOR JITTER PE-TO-PE TUNNEL

\begin{tabular}{|l|l|l|l|l|}
\hline \multicolumn{5}{|l|}{ Summary } \\
\hline Groups & Count & Sum & Average & Variances \\
\hline Auto PE & 54000 & 1.40654 & 2604703 & 4.27 \\
\hline GRE CE & 54000 & 1.40721 & 260533 & 4.3 \\
\hline GRE PE & 54000 & 1.40671 & 2605027 & 4.31 \\
\hline Manual CE & 54000 & 1.40645 & 2604539 & 4.34 \\
\hline Manual PE & 54000 & 1.40654 & 2604703 & 4.27 \\
\hline 6to4 CE & 54000 & 1.40616 & 2603998 & 4.31 \\
\hline Auto CE & 54000 & 1.4059 & 2603527 & 4.32 \\
\hline 6to4 PE & 54000 & 1.40671 & 2605027 & 4.3 \\
\hline ISATAP CE & 54000 & 1.41517 & 2613775 & 4.32 \\
\hline ISTAP PE & 54000 & 1.41622 & 2632852 & 4.36 \\
\hline
\end{tabular}

(contd.)

\begin{tabular}{|c|c|c|c|c|c|c|}
\hline $\begin{array}{l}\text { Source of } \\
\text { variation }\end{array}$ & $S S$ & $D f$ & $M S$ & $F$ & $\begin{array}{l}p \text { - } \\
\text { value }\end{array}$ & $F$-critical \\
\hline $\begin{array}{l}\text { Between } \\
\text { Groups }\end{array}$ & 2.49 & 10 & 2.49 & \multirow{3}{*}{0.005791} & \multirow{3}{*}{1} & \multirow{3}{*}{$\begin{array}{l}1.83072 \\
\text { FTEST<FC } \\
\text { RITICAL } \\
\text { Accept Null } \\
\text { Hypothesis }\end{array}$} \\
\hline $\begin{array}{l}\text { Within } \\
\text { Groups }\end{array}$ & 2.55 & 593989 & 4.3 & & & \\
\hline Total SST & 2.55 & 593999 & & & & \\
\hline
\end{tabular}

\section{Summarized Result}

The statistical analysis for delay, jitter, and throughput was performed to identify if there is a statistically-significant difference among these scenarios and if so to determine which one(s) are the superior methods, in the order of best to worst. The detailed analysis is described in the above Analysis.

The results for delay including the ordinal ranking values are shown in Table XIV.

1) Lowest to highest delay ipv6 transition mechanism: The results for delay including ordinal ranking values are shown in Table XIV shows that ISATAP PE having lowest delay and 6to4 CE is highest delay.

2) Lowest to highest jitter ipv6 transition mechanism: The results for delay including ordinal ranking values are shown in Table XV shows that ISATAP PE having lowest jitter and 6to4 CE is highest delay.

For throughput, the analysis shows that there is no statistically significant difference among the all mechanisms. Next the main objective of this research is analyzed, which is to rank the aforementioned IPv6 transition mechanisms from best to worst as shown in below Table XVI. The best mechanism offers lowest delay, lowest jitter, and highest throughput.

3) Best to worst overall ipv6 transition mechanism: The result shows that ISATAP PE has the best overall performance metrics with lowest delay lowest jitter and highest throughput.

TABLE. XIV. Lowest to Highest Delay IPV6 Transition Mechansim

\begin{tabular}{|l|l|}
\hline $\begin{array}{l}\text { IPv6 Transition Mechanisms in Order of Lowest to } \\
\text { Highest Delay }\end{array}$ & $\begin{array}{l}\text { Ordinal Ranking } \\
\text { Value }\end{array}$ \\
\hline $\begin{array}{l}\text { ISATAP PE Delay (0.00204793) jitter (0.001603592) } \\
\text { Throughput (2632852) }\end{array}$ & 1 \\
\hline Manual PE-to-PE and Automatic PE-to-PE & 2 \\
\hline 6to4 PE-to-PE and GRE PE-to-PE & 4 \\
\hline Manual CE-to-CE and Automatic CE-to-CE & 6 \\
\hline 6to4 CE-to-CE and ISATAP CE & 8 \\
\hline 6to4 CE (0.002133757) & 10 \\
\hline
\end{tabular}

TABLE. XV. LOWESt to Highest JitTer IPV6 Transition Mechansim

\begin{tabular}{|l|l|}
\hline $\begin{array}{l}\text { IPv6 Transition Mechanisms in Order of Lowest to } \\
\text { Highest Jitter }\end{array}$ & $\begin{array}{l}\text { Ordinal Ranking } \\
\text { Value }\end{array}$ \\
\hline ISATAP PE ( 0.001603592) & 1 \\
\hline Manual CE-to-CE and Automatic CE-to-CE & 2 \\
\hline $\begin{array}{l}\text { Manual PE-to-PE, Automatic PE-to-PE, 6to4 PE-to- } \\
\text { PE, and GRE PE-to-PE }\end{array}$ & 4 \\
\hline 6to4 CE-to-CE and ISATAP CE & 8 \\
\hline GRE CE (0.001654 ) & 10 \\
\hline
\end{tabular}


TABLE. XVI. Best to Worst OVERALl IPv6 TRansition Mechanism

\begin{tabular}{|l|l|l|}
\hline $\begin{array}{l}\text { Overall (including delay, jitter, and } \\
\text { throughput) IPv6 Transition } \\
\text { Mechanisms in Order of Best to Worst }\end{array}$ & $\begin{array}{l}\text { Ordinal } \\
\text { Ranking Value }\end{array}$ & $\begin{array}{l}\text { Overall } \\
\text { Ranking }\end{array}$ \\
\hline $\begin{array}{l}\text { ISATAP PE Delay (0.00204793) jitter } \\
(0.001603592) \text { Throughput (2632852) }\end{array}$ & 1 & 1 \\
\hline $\begin{array}{l}\text { Manual PE-to-PE and Automatic PE-to- } \\
\text { PE }\end{array}$ & 13 & 6 \\
\hline $\begin{array}{l}\text { Manual CE-to-CE, Automatic CE-to-CE, } \\
\text { 6to4 PE-to-PE, and GRE PE-to-PE }\end{array}$ & 14 & 7 \\
\hline 6to4 CE-to-CE , ISATAP CE & 21 & 10 \\
\hline GRE CE-to-CE & 23 & 11 \\
\hline
\end{tabular}

\section{VII.CONCLUSION}

This paper has two phases of contribution, i.e., connectivity of IPv4 and IPv6; secondly, test performance of different tunneling techniques. From the above simulation test result, ISATAP PE is best because of the high throughput and lowest jitter during data packets transmission. Whereas GRE $\mathrm{CE}$ is worst due to its high jitter and lowest throughput in the network. The main objective is to provide IPv6 connectively and test which tunneling technique is better to have better performance than others. Future work can extend in payload of the network. Additionally security of these tunneling techniques can be analyzed.

\section{REFERENCES}

[1] R. Tadayoni,and A. Henten, 'From IPv4 to IPv6: Lost in translation?', In Telematics and Informatics, vol. 33, the year 2016, Issue 2, pp 650-659.

[2] L. Smith, M. Jacobi and S. Al-Khayatt, "Evaluation of IPv6 transition mechanisms using QoS service policies", 2018 11th International Symposium on Communication Systems, Networks \& Digital Signal Processing (CSNDSP), Budapest, Hungary, 2018, pp. 1-5.

[3] M. Nikkhah, "Maintaining the progress of IPv6 adoption", In Computer Networks, vol 102, 2016, pp 50-69.

[4] N. Zhang, M. A. Sirbu and J. M. Peha, "A comparison of migration and multihoming support in IPv6 and XIA", 2017 International Symposium on Networks, Computers, and Communications (ISNCC), Marrakech, 2017, pp. 1-8.

[5] Kamaldeep, M. Malik and M. Dutta, "Implementation of single-packet hybrid IP traceback for IPv4 and IPv6 networks", IET Information Security, vol. 12, no. 1,year 2018, pp. 1-6.
[6] D. R. Al-Ani, A. R. Al-Ani, "The Performance of IPv4 and IPv6 in Terms of Routing Protocols using GNS 3 Simulator", Procedia Computer Science, Vol 130, 2018, Pages 1051-1056.

[7] J. Beeharry and B. Nowbutsing, "Forecasting IPv4 exhaustion and IPv6 migration", 2016 IEEE International Conference on Emerging Technologies and Innovative Business Practices for the Transformation of Societies (EmergiTech), Balaclava, 2016, pp. 336-340.

[8] Y. Sookun,and V. Bassoo, "Performance analysis of IPv4/IPv6 transition techniques",2016 IEEE International Conference on Emerging Technologies and Innovative Business Practices for the Transformation of Societies (EmergiTech), Balaclava, year 2016 pp. 188-193.

[9] R. Z. Khan, and A. Shiranzaei, "IPv6 security tools-A systematic review", 2016 International Conference on Computing, Communication and Automation (ICCCA), Noida, 2016, pp. 459-464. The Illustrated.

[10] Network How TCP/IP Works in a Modern Network Book2nd Edition year 2017 by Walter Goralski.

[11] V. Kher, A. Arman and D. S. Saini, "Hybrid evolutionary MPLS Tunneling Algorithm based on high priority bits," Futuristic Trends on Computational Analysis and Knowledge Management (ABLAZE), 2015 International Conference on, Noida, 2015.

[12] The Illustrated Network How TCP/IP Works in a Modern Network Book2nd Edition year 2017 by Walter Goralski.

[13] Hamarsheh, and Ala,"Deploying IPv4-only Connectivity across Local IPv6-only Access Networks”, IETE Technical Review Taylor \& Francis year 2018, pp. 1-14.

[14] Technologies and Innovative Business Practices for the Transformation of Societies (EmergiTech), Balaclava, 2016, pp. 336-340.

[15] Y. Sookun,and V. Bassoo, "Performance analysis of IPv4/IPv6 transition techniques",2016 IEEE International Conference on Emerging Technologies and Innovative Business Practices for the Transformation of Societies (EmergiTech), Balaclava, year 2016 pp. 188-193.

[16] R. Z. Khan, and A. Shiranzaei, "IPv6 security tools-A systematic review", 2016 International Conference on Computing, Communication and Automation (ICCCA), Noida, 2016, pp. 459-464.

[17] The Illustrated Network How TCP/IP Works in a Modern Network Book2nd Edition year 2017 by Walter Goralski.

[18] Hamarsheh, and Ala,"Deploying IPv4-only Connectivity across Local IPv6-only Access Networks", IETE Technical Review Taylor \& Francis year 2018, pp. 1-14.

[19] F. Siddika, and M. A. Hossen , and S. Saha, "Transition from IPv4 to IPv6 in Bangladesh: The competent and enhanced way to follow", 2017 International Conference on Networking, Systems and Security(NSysS), Dhaka, year 2017, pp. 174-179. 